\title{
Determination of focal depth by two waveform- based methods: A case study for the 2008 Panzhihua earthquake*
}

\author{
Zhenjie Wang $^{1}$ Jiajun Chong ${ }^{1,2, \uparrow}$ Sidao $\mathrm{Ni}^{3}$ and Barbara Romanowicz ${ }^{2}$ \\ ${ }^{1}$ Mengcheng National Geophysical Observatory, University of Science and Technology of \\ China, Hefei 230026, China \\ ${ }^{2}$ Berkeley Seismological Laboratory, 215 McCone Hall, University of California-Berkeley, \\ Berkeley, CA 94720, USA \\ ${ }^{3}$ CAS Key Laboratory of Dynamical Geodesy, Institute of Geodesy and Geophysics, \\ Wuhan 430077, China
}

\begin{abstract}
With the $2008 M_{\mathrm{S}} 6.1$ Panzhihua earthquake as a case study, we demonstrate that the focal depth of the main shock can be well constrained with two approaches: (1) using the depth phase sPL and (2) using full waveform inversion of local and teleseismic data. We also show that focal depths can be well constrained using the depth phase sPL with single broadband seismic station. Our study indicates that the main shock is located at a depth of $11 \mathrm{~km}$, much shallower than those from other studies, confirming that the earthquake occurs in upper crust. Aftershocks are located in the depth range of 11-16 km, which is consistent with a ruptured near vertical fault whose width is about $10 \mathrm{~km}$, as expected for an $M_{\mathrm{S}} 6.1$ earthquake.
\end{abstract}

Key words: Panzihua earthquake; focal depth; waveform inversion; depth phase; waveform comparison method

CLC number: P315. $3^{+} 3$ Document code: A

\section{Introduction}

On August 30, 2008, an $M_{\mathrm{S}} 6.1$ earthquake occurred near Panzhihua city and Huili county, Sichuan Province (hereafter referred to as the Panzhihua earthquake). It is a significant event in Sichuan-Yunnan area after the $M_{\mathrm{S}} 8.0$ Wenchuan earthquake on May 12 , 2008. Both the main shock and its $M_{\mathrm{L}} 5.7$ aftershock are proposed to be on the Yuanmou-Lüzhijiang fault, because the aftershocks show a pattern along a northsouth direction that is consistent with the fault's strike (Long et al., 2010). Accurate location and focal depth of earthquakes in this region is important for studies of seismotectonic of Sichuan-Yunnan area, which may be strongly affected by channel flow of the Tibetan plateau (Royden et al., 1997). There are some previous

\footnotetext{
* Received 6 July 2011; accepted in revised form 2 August 2011; published 10 August 2011.

* Corresponding author. e-mail: jiajunchong@gmail.com

(c) The Seismological Society of China and Springer-Verlag Berlin Heidelberg 2011
}

studies of earthquake location and depth in this region, for example, Yang et al. (2003) relocated earthquakes in central-western China. The Panzhihua earthquake sequence provides us an opportunity to study properties of the Yuanmou-Lüzhijiang fault and thus helps us understand the seismogenic processes of this region.

However, there is a controversy over the focal depth of the main shock, which is a crucial parameter to constrain the brittle-ductile transition depth in this region. Moreover accurate focal depth is also important for strong ground motion studies. The focal mechanisms provided by USGS and GCMT are similar, and feature near vertical strike slip faulting. However the focal depths from the two agencies are quite different, which are $17.0 \mathrm{~km}$ and $24.1 \mathrm{~km}$, respectively. The focal depth of $24.1 \mathrm{~km}$ may imply strong middle crust that is capable of generating earthquake ruptures. Moreover, some studies based on waveform modeling suggested a much shallower depth (Long et al., 2010). Thus it is important to study focal depths of the main shock and aftershocks 
of the Panzhihua earthquake sequence.

Generally, focal depth can be estimated from travel times of direct phases (e.g. Pg, Sg), or from waveform inversion (Zhao and Helmberger, 1994; Dreger and Helmberger, 1993). These methods may have poor precision of focal depth when applied in the regions where only sparse stations are available or due to uncertainty of the velocity models. In contrast, precise depth can be constrained from differential time between direct phase and their depth phases (e.g. pP, sP, sPg, sPmP, sPn, sPL). In this paper, two approaches are employed to obtain reliable focal depth of the Panzhihua earthquake. First, full waveform inversion of local and teleseismic waveforms with CAP (Cut and Paste) method is used to invert for the focal mechanism and focal depth of the main shock. Then, a waveform comparison method (WCM) with a recently proposed depth phase sPL (Chong et al., 2010 ) is verified with the focal depth from waveform inversion. After that, we estimated depths of six $M 4+$ aftershocks using the sPL phase observed at a station located about $37 \mathrm{~km}$ from the main shock.

The rest of this paper is organized as follows. Section 2 gives a brief introduction to the Panzhihua earthquake. Section 3 presents the focal mechanism and depth of the main shock using local and teleseismic w- hole waveform inversion. The focal depths of the main shock and six aftershocks using the depth phase sPL are presented in section 4 . In Sections 5 and 6 , we present a discussion and conclusions of this study.

\section{Panzhihua earthquake}

As of January in 2009, about 1700 aftershocks were recorded by the regional seismic network of Sichuan Province, with two aftershocks between M5.0 and $M 5.9$, and four aftershocks between $M 4.0$ and M4.9 (Figure 1). The main shock is well located in the middle segment (from Xigeda to Hongge) of the Yuanmou-Lüzhijiang fault. The distribution of aftershocks shows a pattern of about $30 \mathrm{~km}$ length along the north-south direction which is consistent with the fault's strike (Long et al., 2010). Starting from Mianning in the north and ends in the south of Yuanmou, the Yuanmou-Lüzhijiang fault is a $240 \mathrm{~km}$ left-lateral strike-slip fault with minor component of thrust (Liu, 2008). Developed in the late Quaternary, this fault is active and one of the important secondary structural units in Yunnan-Sichuan area. The Panzhihua earthquake presents a valuable opportunity for studying the properties of this fault.
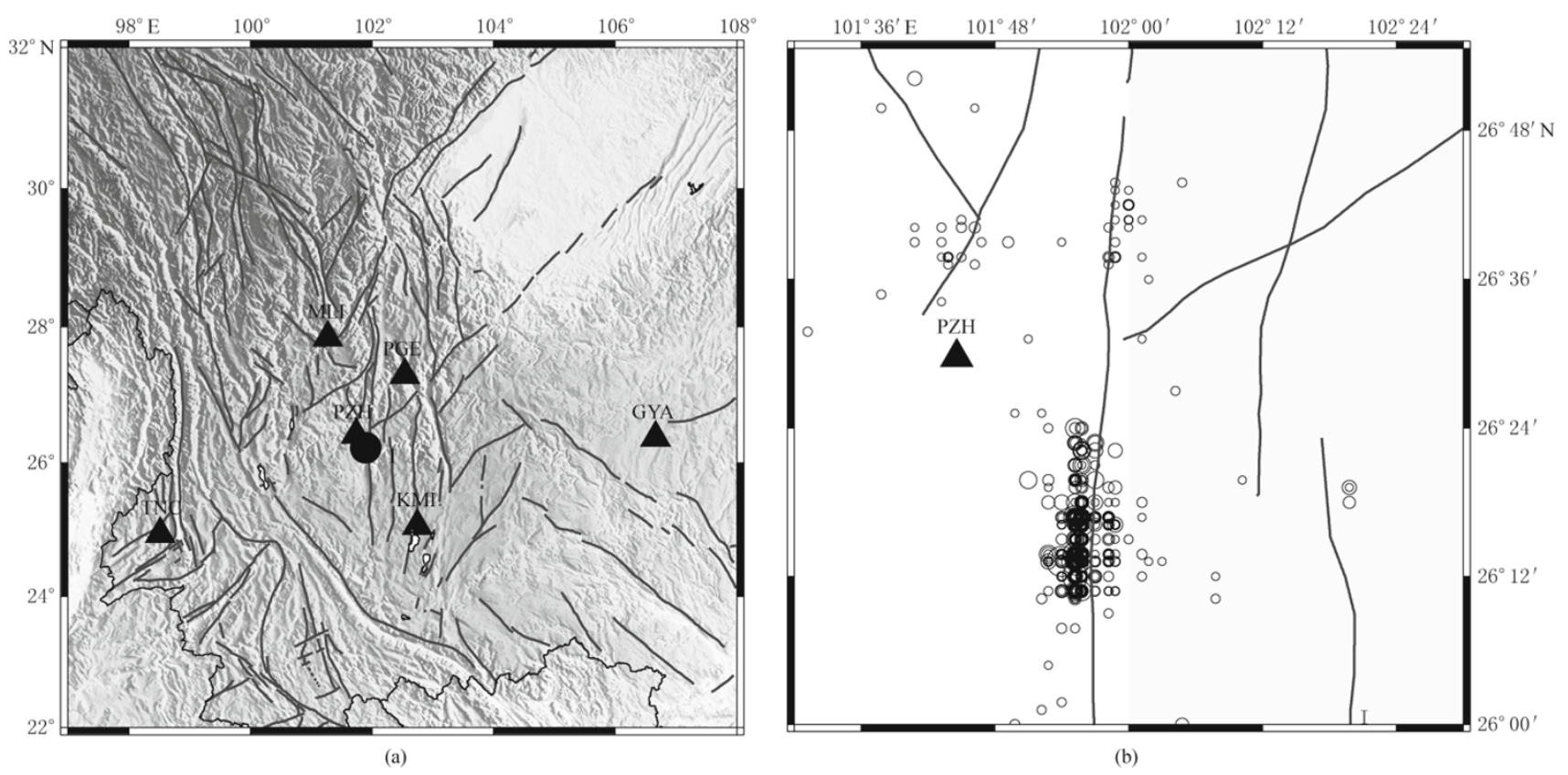

Figure 1 Epicenter of the main shock (solid circle) and seismic stations (triangles) overlaid topography (a); Location of the Panzhihua (PZH) station (triangle) and distribution of aftershocks (open circles) and fault traces (lines). 


\section{Focal depth and mechanism from waveform inversion}

We use a modified version of CAP (cut and paste) method (Zhao and Helmberger, 1994; Zhu and Helmberger, 1996) to invert for the focal mechanism and depth of the main shock by fitting local and teleseismic waveforms simultaneously.

The original CAP method is a full waveform inversion method for focal mechanism and focal depth with local seismic data (epicentral distances typically less than $500 \mathrm{~km}$ ). It breaks the waveforms into segments of Pnl and surface waves, and assigns separate weights for the waveform segments and allows slight time shifts between data and synthetics. Thus it has the advantage that only a few stations are required and the results are less affected by uncertainty of the velocity model used for calculating Green's functions. For $M 4+$ earthquakes recorded at one station within 100 $\mathrm{km}$, focal depth is typically well constrained with CAP because Pnl waves contains depth phases. Moreover, the ratio of body wave and surface waves is also adopted in CAP to provide more constraints on focal depth.

Along with local waveforms, teleseismic data provides additional sampling of take-off angle on the focal sphere, thus leading to better focal mechanisms. Moreover, teleseismic depth phases $\mathrm{sP}$ and $\mathrm{pP}$ provide extra constraints over focal depth. Especially for a near vertical fault, teleseismic data can constrain the dip angle very well because of the small take-off angle of $\mathrm{P}$ and $\mathrm{SH}$ waves. Also teleseismic data of moderate earthquakes (larger than M5) usually have a high signal to noise ratio (SNR), so here we modify the CAP method to invert local and teleseismic waveforms simultaneously.

Local and teleseismic data of the main shock are collected for six local broadband stations (Figure 1a) and 17 IRIS/GSN teleseismic stations (Figure 2). Five segments of local waveforms are used for inversion, i.e., the vertical and radial components of Pnl, the vertical and radial components of Rayleigh wave, and the tangential component of Love wave. For teleseismic waveform data, we use the vertical component of $\mathrm{P}$ wave and the tangential component of $\mathrm{S}$ wave (SH). Therefore only two segments of waveforms are used for teleseismic data at each station. During the joint inversion, local and teleseismic waveform data are weighted according to the following equation,

$$
\frac{E_{\mathrm{loc}}}{N_{\mathrm{loc}} \cdot \sigma_{\mathrm{loc}}^{2}}=\frac{E_{\mathrm{tel}}}{N_{\mathrm{tel}} \cdot \sigma_{\mathrm{tel}}^{2}}
$$

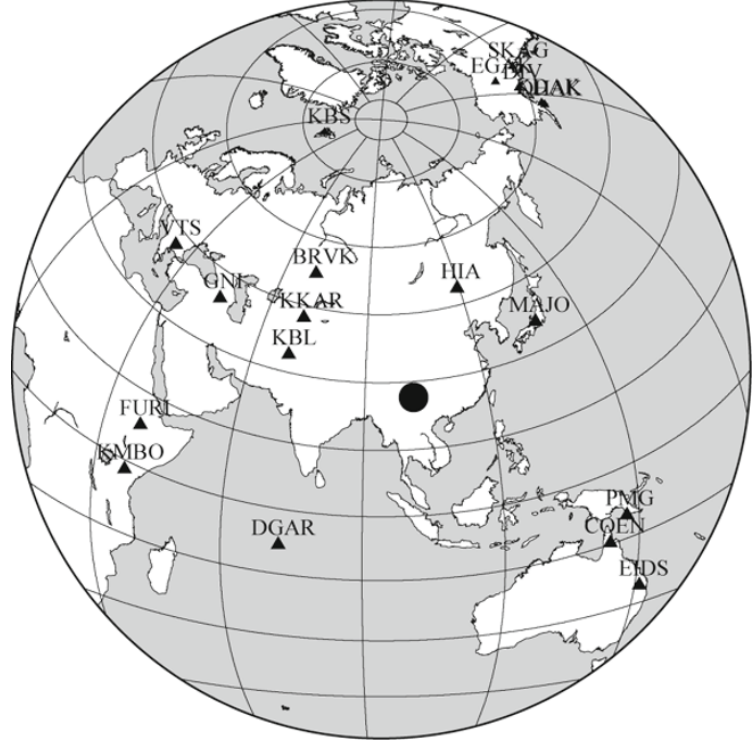

Figure 2 Distribution of teleseismic IRIS/GSN broadband stations (triangles) and location of main shock (solid circle).

where $\sigma_{\text {loc }}^{2}$ and $\sigma_{\text {tel }}^{2}$ are misfit variances of local and teleseismic waveforms respectively, and they quantify how applicable the velocity model is. $E_{\mathrm{loc}}$ and $E_{\mathrm{tel}}$ represent the misfits between data and synthetic waveforms. $N_{\text {loc }}$ and $N_{\text {tel }}$ are the number of waveforms. The velocity model (Table 1) for calculating local and teleseismic Green's functions is constructed by taking the average of a 2D profile from a deep seismic sounding study in west Panzhihua (Xiong et al., 1993). The same model is used for determining focal depth with depth phase sPL. Both data and synthetic waveforms are filtered in the same frequency band with a 4th order Butterworth filter, $0.03-0.1 \mathrm{~Hz}$ for Pnl and surface waves of local waveforms, and $0.02-0.1 \mathrm{~Hz}$ for teleseismic $\mathrm{P}$ and $\mathrm{SH}$.

Table 1 Velocity model

\begin{tabular}{cccc}
\hline Depth $/ \mathrm{km}$ & $v_{\mathrm{S}} / \mathrm{km} \cdot \mathrm{s}^{-1}$ & $v_{\mathrm{P}} / \mathrm{km} \cdot \mathrm{s}^{-1}$ & Density $/ \mathrm{g} \cdot \mathrm{cm}^{-3}$ \\
\hline $0-10.6$ & 3.50 & 6.06 & 2.71 \\
$10.6-19.1$ & 3.57 & 6.18 & 2.75 \\
$19.1-30.0$ & 3.67 & 6.35 & 2.80 \\
$30.0-39.2$ & 3.24 & 5.60 & 2.56 \\
$39.2-53.7$ & 3.86 & 6.68 & 2.91 \\
$53.7-$ & 4.50 & 7.78 & 3.26 \\
\hline
\end{tabular}

The joint inversion of local and teleseimsic waveforms shows that the Panzhizhua earthquake is predominantly a strike-slip earthquake. And the variation of misfit with focal depth in Figure 3 shows that the best estimate of focal depth is $11 \mathrm{~km}$. At this depth both local and teleseismic datasets are matched by syn- 
thetic seismograms very well (Figure 4). At this depth, the two fault plane solutions (strike/dip/rake) are, I: $194^{\circ} / 78^{\circ} / 12^{\circ}$ and II: $102^{\circ} / 78^{\circ} / 168^{\circ}$, respectively. Fault plane I should be the ruptured fault plane since it is consistent with the geometry of the Yuanmou-Lüzhijiang fault and the distribution of aftershocks (Figure 1). The moment magnitude is 5.9 , which is consistent with $M_{\mathrm{W}} 6.0$ from global CMT. The minor difference in

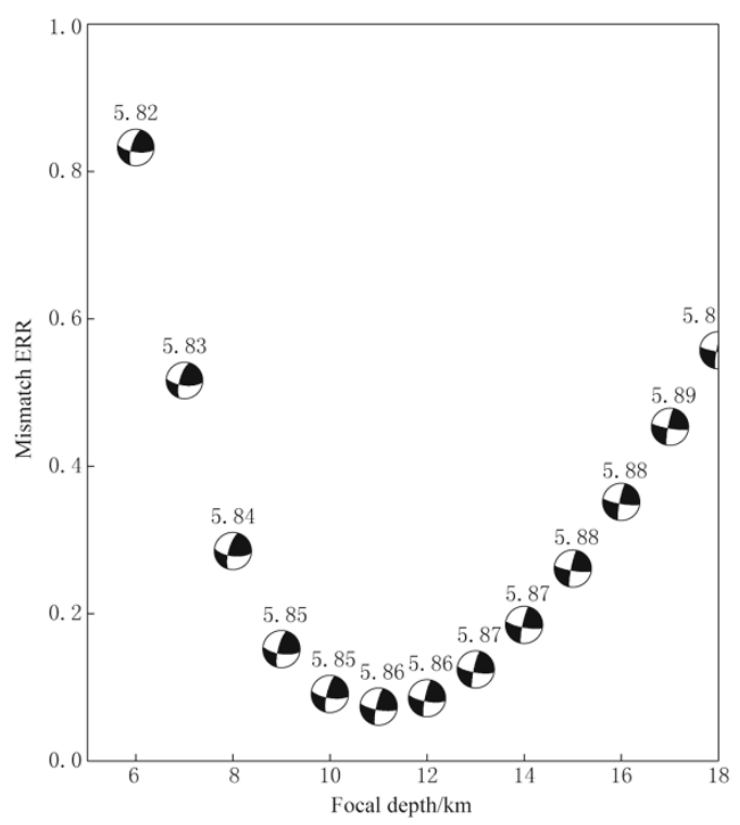

Figure 3 Variation of normalized misfit vs focal depth of the Panzhihua earthquake. Moment magnitude and focal mechanism are shown for each depth as well.

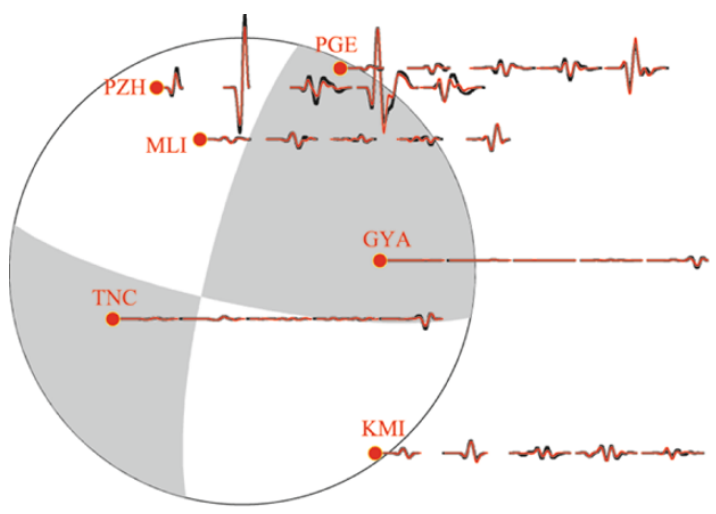

(a) moment magnitude may be due to inaccurate $t^{*}$ used in computing the teleseismic body waves (for our study, $t_{\mathrm{P}}^{*}$ is chosen to be $1.0 \mathrm{~s}$, and $t_{\mathrm{S}}^{*}$ is $4.0 \mathrm{~s}$, which is usually adopted in teleseismic waveform modelings, Kikuchi and Kanamori, 1982).

\section{Focal depths from depth phase SPL}

The differential times between local depth phases and their direct phases are sensitive to focal depth but insensitive to epicentral distance, thus can be used to constrain focal depth. Since only differential time is involved, the absolute origin of earthquakes is not required for the depth phase method. Moreover, for the regions that can be well modeled with $1 \mathrm{D}$ velocity structure, focal depth can be well constrained with single station using depth phases. Thus they are very helpful for the regions where only sparse seismic stations are available. For the case of half space velocity models, the depth phase $\mathrm{sPL}$ is a phase that is generated when the upgoing $\mathrm{S}$ wave is post-critically converted into a $\mathrm{P}$ wave along the free surface. And in the case of substantial velocity gradient near the free surface, sPL also may contain turning waves corresponding to multiple conversion or reverberations in shallow structure near the free surface. sPL lags $\mathrm{P}$ wave and arrives earlier than $\mathrm{S}$ waves, and it is stronger on the radial component than on the vertical component because of its near horizontal incidence. As sPL is generated by conversion

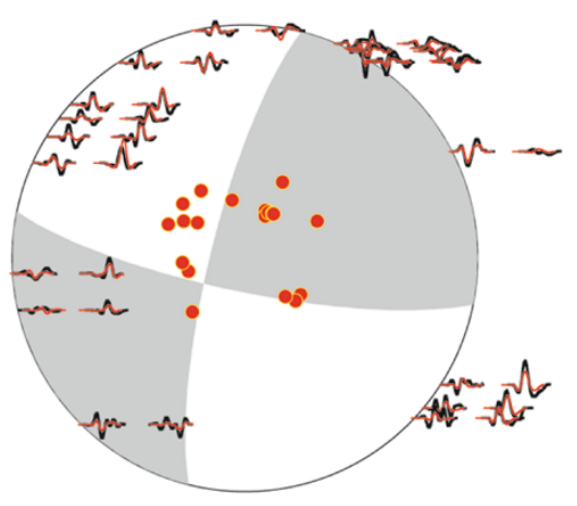

(b)

Figure 4 Waveform fitting between synthetics (red) and observations (black) for the Panzhihua earthquake with focal depth at $11 \mathrm{~km}$ for synthetics. (a) Five segments of local waveforms are the vertical and radial component of Pnl, the vertical and radial component of Rayleigh wave, and the tangential component of Love wave. The waveforms are filtered in the frequency range $0.03-0.1 \mathrm{~Hz}$ with a 4 th order Butterworth filter. (b) Teleseismic waveforms: vertical component of $\mathrm{P}$ wave and tangential component of SH wave. They are filtered in the frequency range $0.02-0.1 \mathrm{~Hz}$ with 4 th order Butterworth filter. 
between $\mathrm{SV}$ and $\mathrm{P}$ waves, it is very weak on the tangential component. It is usually well observed in the distance range less than $50 \mathrm{~km}$, depending on the focal depth and velocity structure. And sPL phase has been successfully used to determine focal depth with only one station at near distance (Chong et al., 2010). In Figure
5 , we show the ray path of sPL for the simplest case (half space velocity model), and Green's functions calculated with FK method (Saikia, 1994; Wang and Herrmann, 1980; Zhu and Rivera, 2002) for the model as specified in Table 1 to show the variation of the differential time between sPL and $\mathrm{P}$ with focal depth.

(a)

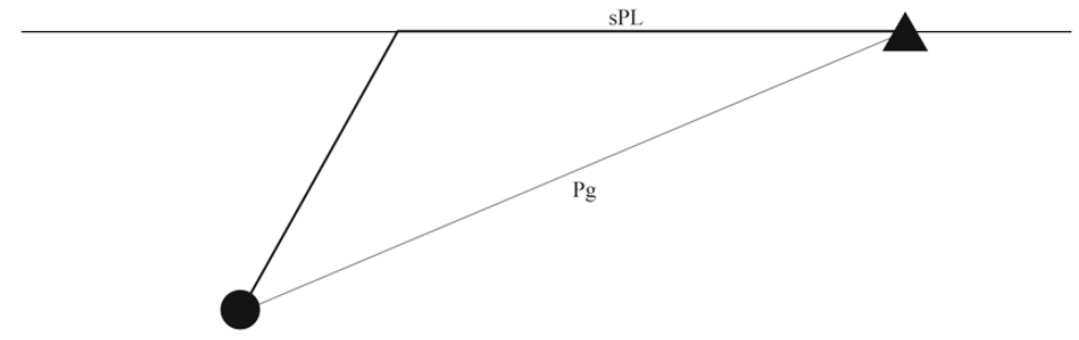

(b)
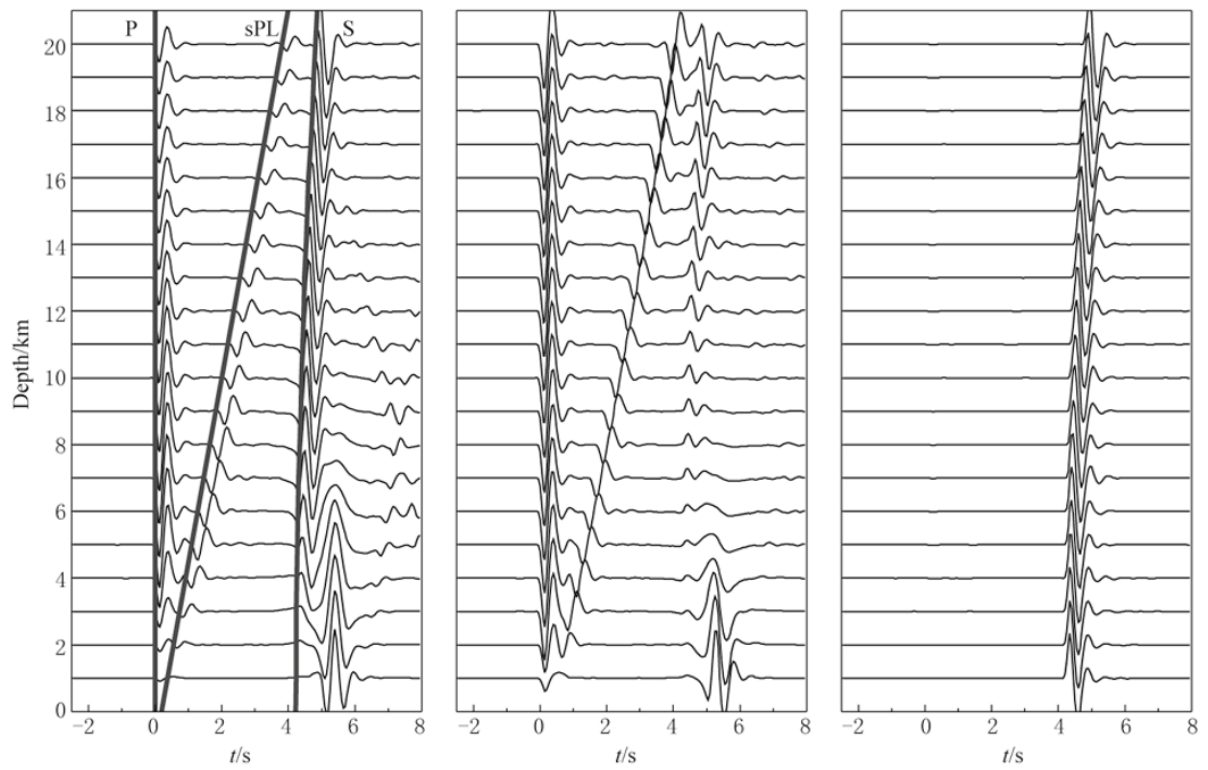

Figure 5 Ray path of sPL for half space model (a). sPL phase depth sensitivity test at a fixed epicentral distance of $37 \mathrm{~km}$ (b). Three components Green's functions of a strike-slip double couple source are low-pass filtered with a corner at $2 \mathrm{~Hz}$. The seismograms are aligned with $\mathrm{P}$ arrival. From left to right: vertical, radial, tangential components.

For PZH station which is about $37 \mathrm{~km}$ away from the main shock, we observed obvious sPL from the main shock and its six aftershocks (Figure 6). Following the approach of Chong et al. (2010), we calculated synthetic waveforms for each earthquake at different focal depths and determine the best focal depth with the waveform comparison method (WCM). With this method, we can obtain good estimate of the differential time between $\mathrm{sPL}$ and direct $\mathrm{P}$. The waveform comparison is carried out by comparing radial component of observed seismograms with synthetics. Synthetic waveforms are calculated with focal mechanism of the main shock, since focal mechanisms of aftershocks are similar to that of main shock (Long et al., 2010).

Our estimate of focal depth for the main shock is also $11 \mathrm{~km}$ from the sPL depth phase analysis, suggesting that sPL is an effective depth phase. Therefore estimates of focal depths of aftershocks should be reliable with sPL phase. As shown in Figure 7, differential times between $\mathrm{sPL}$ and the direct $\mathrm{P}$ are well fitted for all events. In Table 2, we see that focal depths of some events such as evt_0 (main shock), evt_2, evt_4, from our study are quite different from those of CENC catalog. 


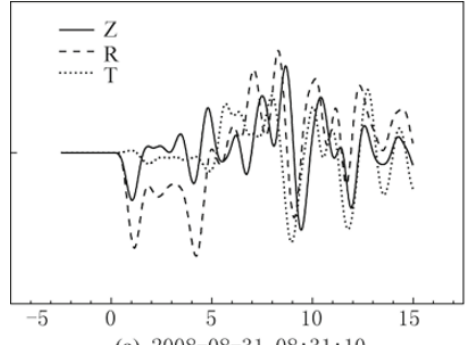

(a) 2008-08-31 08:31:10

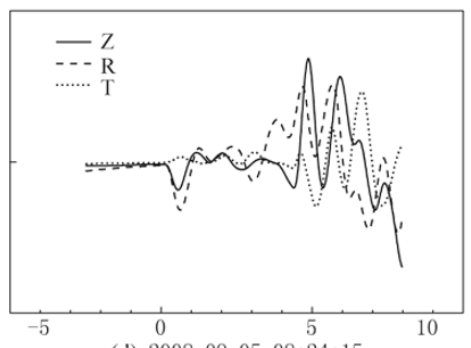

(d) 2008-09-05 08:24:15

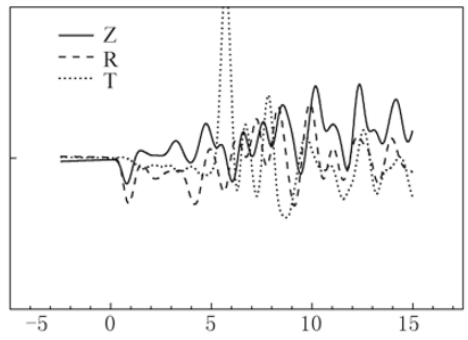

(b) 2008-08-31 09:34:49

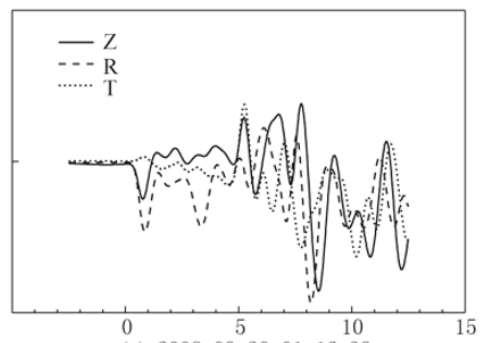

(e) 2008-09-30 01:16:38

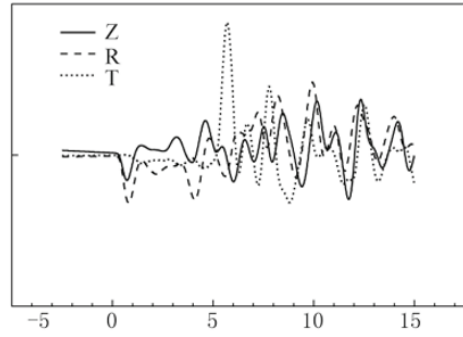

(c) 2008-08-31 11:00:30

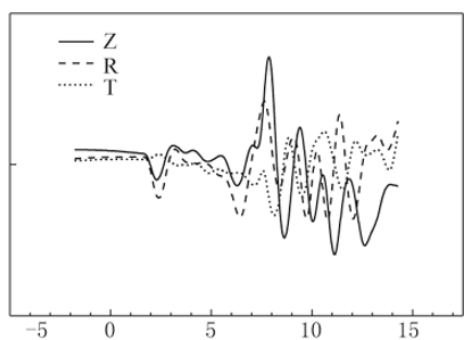

(f) 2008-10-25 02:13:59

Figure 6 Observations of sPL phase. Three component records of displacement filtered by a band-pass with corners at $0.01-1 \mathrm{~Hz}$ of six aftershocks recorded at PZH station.

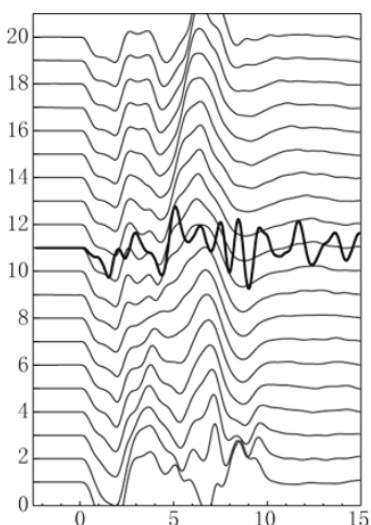

(a) 2008-08-30 08:30:52

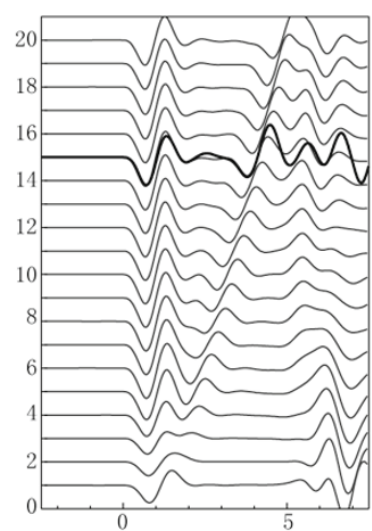

(b) 2008-08-31 08:31:10

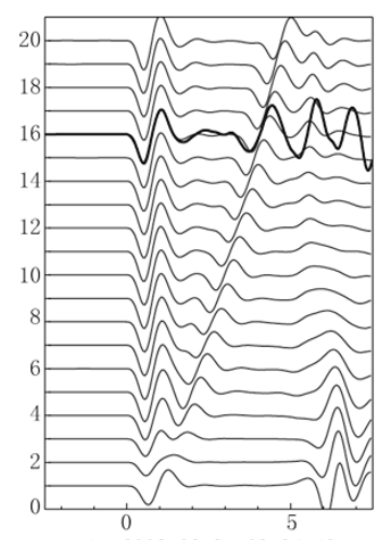

(c) 2008-08-31 09:34:49

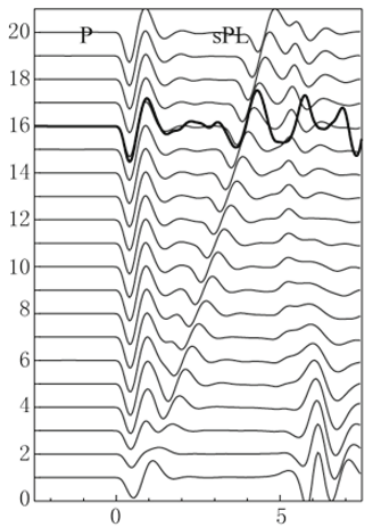

(d) 2008-08-31 11:00:30

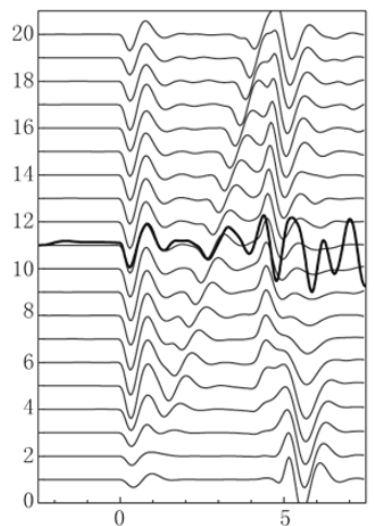

(e) 2008-09-05 08:24:15

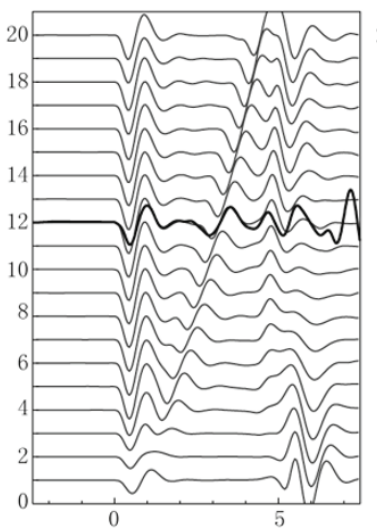

(f) 2008-09-30 01:16:38

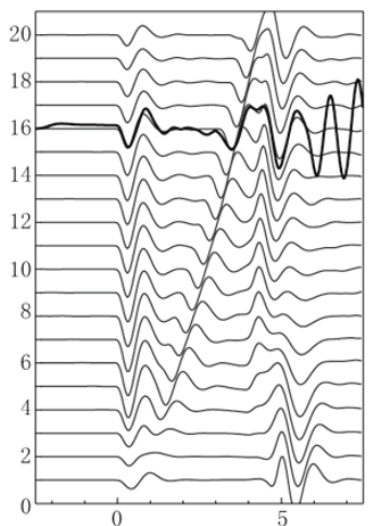

(b) 2008-10-25 02:13:59

Figure 7 Focal depth determinations for main shock and the six aftershocks. Radial components are used for waveform comparison by fitting the differential time between sPL and direct P. Gray for synthetics and black for data. Both data and synthetics are filtered by a band-pass with corners at $0.01-1 \mathrm{~Hz}$. 
Table 2 Focal depths from sPL depth phase and from catalog by China Earthquake Network Center (CENC)

\begin{tabular}{|c|c|c|c|c|c|c|c|}
\hline \multirow[b]{2}{*}{ Event ID } & \multicolumn{2}{|c|}{ Origin time (UTC) } & \multicolumn{2}{|c|}{ Location } & \multirow{2}{*}{$\begin{array}{l}\text { Depth from } \\
\text { sPL/km }\end{array}$} & \multirow{2}{*}{$\begin{array}{l}\text { Depth from } \\
\text { CENC/km }\end{array}$} & \multirow{2}{*}{$\begin{array}{c}\text { Source duration } \\
\text { time } / \mathrm{s}\end{array}$} \\
\hline & $\begin{array}{c}\text { Date } \\
\text { a-mo-d }\end{array}$ & $\begin{array}{c}\text { Time } \\
\text { h:min:s }\end{array}$ & Long $/{ }^{\circ} \mathrm{E}$ & Lat $/{ }^{\circ} \mathrm{N}$ & & & \\
\hline Evt_0 & 2008-08-30 & $08: 30: 52$ & 102.06 & 26.30 & 11 & 19 & 3.5 \\
\hline Evt_1 & 2008-08-31 & $08: 31: 10$ & 102.06 & 26.27 & 15 & 13 & 1.0 \\
\hline Evt_2 & 2008-08-31 & $09: 34: 49$ & 102.06 & 26.25 & 16 & 12 & 0.6 \\
\hline Evt_3 & 2008-08-31 & 11:00:30 & 101.99 & 26.16 & 16 & 14 & 0.4 \\
\hline Evt_4 & 2008-09-05 & $08: 24: 15$ & 101.98 & 26.23 & 11 & 16 & 0.2 \\
\hline Evt_5 & 2008-09-30 & $01: 16: 38$ & 101.94 & 26.24 & 12 & 13 & 0.4 \\
\hline Evt_6 & $2008-10-25$ & $02: 13: 59$ & 102.01 & 26.21 & 16 & 15 & 0.2 \\
\hline
\end{tabular}

\section{Discussion}

As shown in Table 3, focal mechanism of the main shock from our study is similar to that of USGS and GCMT, but different in dip angle (assuming that fault plane I is the ruptured fault plane). Field investigations indicated that the middle segment (from Xigeda to
Hongge) of the Yuanmou-Lüzhijiang fault has a dip angle of about $73^{\circ}$ (Liu, 2008), so our focal mechanism is closer to the fault geometry from the field study. More accurate dip from our study suggests that teleseismic waveforms can constrain the dip angle of near vertical faults very well because of their small take-off angles.

Table 3 Parameters of the main shock

\begin{tabular}{|c|c|c|c|c|c|c|c|c|c|c|}
\hline \multirow{3}{*}{$\begin{array}{c}\text { Origin time (UTC) } \\
\text { h:min:s }\end{array}$} & \multicolumn{2}{|c|}{ Location } & \multicolumn{6}{|c|}{ Fault plane solutions } & \multirow{3}{*}{$\begin{array}{l}\text { Focal depth } \\
\qquad / \mathrm{km}\end{array}$} & \multirow{3}{*}{ Agency } \\
\hline & \multirow{2}{*}{ Long $/{ }^{\circ} \mathrm{E}$} & \multirow{2}{*}{$\overline{\text { Lat } /{ }^{\circ} \mathrm{N}}$} & \multicolumn{3}{|r|}{ 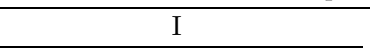 } & \multicolumn{3}{|c|}{ II } & & \\
\hline & & & Strike ${ }^{\circ}$ & $\operatorname{Dip} /{ }^{\circ}$ & Rake $/^{\circ}$ & Strike/ ${ }^{\circ}$ & $\operatorname{Dip} /{ }^{\circ}$ & Rake $/^{\circ}$ & & \\
\hline 08:30:53.01 & 101.88 & 26.24 & 195 & 89 & 19 & 104 & 71 & 179 & 17.0 & USGS \\
\hline $08: 30: 57.50$ & 102.04 & 26.19 & 190 & 90 & 4 & 100 & 86 & 180 & 24.1 & GCMT \\
\hline $08: 30: 52$ & 102.06 & 26.30 & - & - & - & - & - & - & 19 & CENC \\
\hline adopted from CENC & adopted $\mathrm{f}$ & om CENC & 194 & 78 & 12 & 102 & 78 & 168 & 11 & Our study \\
\hline
\end{tabular}

Local and teleseismic waveform inversion and modeling of the depth phase sPL indicate that the main shock is much shallower than that from USGS, GCMT and CENC. As shown in Figure 4, we can fit all the waveforms very well, for both local and teleseismic waveforms, suggesting that our result is reliable. Zhang and $\mathrm{Wu}$ (2008) have determined the focal depth of evt_1 by fitting differential time between $\mathrm{sPn}$ and $\mathrm{Pn}$ with a two layered crustal model. Their estimate of the focal depth is $17 \mathrm{~km}$, close to our result of $15 \mathrm{~km}$. From a comparison with the depths from CENC in Table 2, we find that the depths of some aftershocks (evt_2, evt_4) from our study are quite different from those of CENC catalog. However, we can show that evt_2 is deeper than evt_4 by comparing differential time between sPL and $\mathrm{P}$ of main shock and all the six aftershocks. Since the differential time between SPL and P is insensitive to epicentral distance but increases almost linearly with focal depth, we can arrange aftershocks in the order of focal depth by comparing the differential times between $\mathrm{sPL}$ and P (Figure 7). So, we can conclude that, evt_2, evt_3 and evt_6 are almost at the same depth, but deeper than other events. At the same time, evt_0 and evt_4 are almost at the same depth but shallower than the other earthquakes.

Our study shows that the main shock and six aftershocks $\left(M_{\mathrm{L}} \geq 4.0\right)$ are located in the depth range from 11 to $16 \mathrm{~km}$, with the main shock located at $11 \mathrm{~km}$. From earthquake source dimension scaling law, the main shock should has a rupture dimension (rupture length and width) of about $10 \mathrm{~km}$. Thus the lower depth bound of main shock rupture should be about $16 \mathrm{~km}$ and the upper depth bound of rupture is about $6 \mathrm{~km}$. Usually it is proposed that aftershocks occur around ruptured area of the mainshock, therefore the maximum of $16 \mathrm{~km}$ depth of the aftershocks is consistent with a ruptured vertical fault with centroid at $11 \mathrm{~km}$ that extends $5 \mathrm{~km}$ deeper. As for the absence of big aftershocks with depth less than $6 \mathrm{~km}$, it could be due to that the fault is a mature fault as described by Scholz (2002).

\section{Conclusions}

Focal depth and focal mechanism of Panzhihua earthquake have been determined with local and tele- 
seimic waveform inversion using CAP method. The fault plane solution of the main shock is $194^{\circ} / 78^{\circ} / 12^{\circ}$ (strike/dip/rake), which is similar to that of USGS and GCMT, but a little bit different in dip angle. Compared to the results of a field study (Liu, 2008), our focal mechanism is closer to the fault geometry owing to the fact that we are using both local and teleseismic waveforms for inversion.

For the mainshock, our focal depth is constrained to be $11 \mathrm{~km}$ from waveform inversion and from modeling sPL waveforms. Because teleseismic depth phase such as $\mathrm{pP}$ and $\mathrm{sP}$ suffers less error in the sub-surface velocity structure, focal depth from teleseismic waveform is usually assumed to be more accurate. The consistence of focal depth from waveform inversion and from sPL suggests that sPL is an effective seismic depth for resolving focal depth. The focal depths of six aftershocks $\left(M_{\mathrm{L}} \geq 4.0\right)$ determined with depth phase sPL recorded on a single station, are found to be in the range of 11-16 $\mathrm{km}$. So we conclude that the Panzhihua earthquake sequence is located in the upper crust rather than the middle or lower crust, and the depth of the brittle-ductile transition of the Yuanmou-Lüzhijiang fault is proposed to be no shallower than $17 \mathrm{~km}$ which is the largest depth of all aftershocks in the Panzhihua earthquake sequence.

Though depth phases such as sPL help to constrain focal depth well, but it is still affected by the velocity model used, though the depth error can be reduced to 1-2 $\mathrm{km}$ when a good velocity model is used (Chong et al., 2010; Luo et al., 2010; Wei et al., 2009). Another limitation of using sPL in constraining depth is that $\mathrm{sPL}$ can not be observed when SV wave happens to be near the nodal plane. To make the situation less desirable, regions with substantial topographic variation typically feature very complicated waveforms from $\mathrm{P}$ wave to $\mathrm{S}$ waves, thus demanding further study of topography effects on sPL waveforms.

Acknowledgements This study is financial supported by Joint Seismological Science Foundation of China (No.200808078) and National Natural Science Foundation of China (Nos.40821160549 and 41074032).

\section{References}

Chong J J, Ni S D and Zeng X F (2010). sPL, an effective seismic phase for determining focal depth at near distance. Chinese J Geophys 53: 2 620-2 630 (in Chinese with English abstract).

Dreger D S and Helmberger D V (1993). Determination of source parameters at regional distances with three- component sparse network data. J Geophys Res 98: 8 107-8 125.

Kikuchi M and Kanamori H (1982). Inversion of complex body waves. Bull Seismol Soc Amer 72: 491-506.

Liu M F (2008). A study on genesis of Hongge hot spring in Yanbian, Sichuan Province. Coal Geology Of China 20: 45-48 (in Chinese with English abstract).

Long F, Zhang Y J, Wen X Z, Ni S D (2010). Focal mechanism solutions of $M_{\mathrm{L}} \geq 4.0$ events in the $M_{\mathrm{S}} 6.1$ PanzhihuaHuili earthquake sequence of Aug 30, 2008. Chinese $J$ Geophys 53: 2 852-2 860 (in Chinese with English abstract).

Luo Y, Ni S D, Zeng X F, Zheng Y and Chen Q F (2010). A shallow aftershock sequence in the north-eastern end of the Wenchuan earthquake aftershock zone. Science in China (Series D) 40: 677-687.

Royden L H, Burchfiel B C, King R E, Wang E, Chen Z, Shen F and Liu Y (1997). Surface deformation and lower crustal flow in eastern Tibet. Science 276: 788-790.

Saikia C (1994). Modified frequency-wavenumber algorithm for regional seismograms using Filon's quadrature: model $\mathrm{Lg}$ waves in eastern North America. Geophys $J$ Int 118: $142-158$.

Scholz C H (2002). The Mechanics of Earthquakes and Faulting. Cambridge University Press, Cambridge, 471.

Wang C Y and Herrmann R B (1980). A numerical study of $\mathrm{P}-, \mathrm{SV}-$, and $\mathrm{SH}$-wave generation in a plane layered medium. Bull Seismol Soc Amer 70: 1 015-1 036.

Wei S J, Ni S D, Chong J J, Zheng Y and Chong Y (2009). The 16 August 2003 Chifeng earthquake: Is it a lower crust earthquake?. Chinese J Geophys 52: 111-119 (in Chinese with English abstract).

Xiong S B, Zheng Y, Yin Z X, Zeng X X, Quan Y L and Sun K Z (1993). The 2-D structure and its tectonic implications of the crust in the Lijiang-Panzhihua-Zhehai region. Chinese J Geophys 36: 434-444 (in Chinese with English abstract).

Yang Z X, Chen Y T, Zheng Y J and Yü X W (2003). Accurate relocation of earthquakes in central western China using the double difference earthquake location algorithm. Science in China (Series D) 46: 181-188.

Zhang R Q and Wu Q J (2008). Focal depth for an earthquake $\left(M_{\mathrm{S}} 5.6\right)$ on August 31, 2008 in Panzhihua of Sichuan Province. Recent Developments in World Seismology 12: 1-5 (in Chinese with English abstract).

Zhao L S and Helmberger D V (1994). Source estimation from broadband regional seismograms. Bull Seismol Soc Amer 84: 91-104.

Zhu L P and Helmberger D V (1996). Advancement in source estimation techniques using broadband regional seismograms. Bull Seismol Soc Amer 86: 1 631-1 641.

Zhu L and Rivera L A (2002). A note on the dynamic and static displacements from a point source in multi-layered media. Geophys J Int 148: 619-627. 